\title{
Risks of Protein Conditioner Application under the Impact of Heat and/or Gamma Irradiation in Albino Rats
}

\author{
Eskander, S.B.*, Abdel-Gawad, E. I., Ezz El Arab, A. \\ Radioisotopes Department- Egyptian Atomic Energy Authority, Egypt.
}

\begin{tabular}{l} 
ARTICLE INFO \\
\hline Article history: \\
Received: $20^{\text {th }}$ Dec. 2020 \\
Accepted: $5^{\text {th }}$ Apr. 2021 \\
\hline
\end{tabular}

Keywords:

Protein hair conditioner,

hot air,

$\gamma$ - irradiation,

HSP70,

Col-1.

\author{
ABSTRACT
}

The objective of the submitted work was to assess the effect of hot air and/ or gamma irradiation following the application of a protein hair conditioner on the skin hygiene. Ninety six albino rats were employed in this work, one half of them were females and the other half was males. The animals were divided into eight main groups; each included six males and six females. Rats in group 1 (control) and they were fed free on normal food and water. Rats of groups 2,3 and 4were rubbed with protein conditioner for one, two and three times, respectively, every so often was separated by seven days duration. Following every treatment, the rats were exposed to hot air from a blow dryer $\left(95^{\circ} \mathrm{C}\right)$ for one minute. Rats in groups 5, 6 and 7 were treated in the same manner and after one week, they exposed to a single dose whole body gamma irradiation ( $10 \mathrm{~Gy}$ ). Rats in group 8 were treated once with protein conditioner and they were directly exposed to the same irradiation dose. Post one week of irradiation, all rats were anesthetized and blood samples were collected for biochemical analyses, while shaven skin cuts from the centre protein applying area for histological examinations. Morphological observations revealed decreases in hair density, alopecia and skin ulcer. Whereas, the biochemical results indicated that serum collagen I (Col. I) contents decreased while heat shock protein (HSP70) concentrations increased as treatment repetitions. The level of vascular endothelial growth factor (VEGF) exhibited inconsistence trend. Histopathological observations confirmed the morphological findings particularly the skin ulcer phenomenon.

In conclusion, there is no protein -based hair conditioner products that can be considered completely safe. It is worth to state that, it's time to give serious consideration for stopping these treatments. Even if there are no negative effects as yet are noticed, it doesn't mean that human is immune but cumulative exposure can increase the risks.

\section{INTRODUCTION}

Skin, the most superficial tissue of our body, is the first target of environmental stimuli. Epidermis is the most external and largest layer of our body and plays the most important protective role.[1] The skin is an organ of the integumentary system made up of multiple layers, ectodermic tissue, which guards the underlying muscles, bones, ligaments and internal organs. The epidermis is composed of the outermost layers of the skin and is a stratified squamous epithelium, composed of proliferating basal and differentiated supra basal keratinocytes. It forms a protective barrier over the body's surface, responsible for keeping water in the body and preventing pathogens from entering. The dermis provides tensile strength and elasticity to the skin through an extracellular matrix composed of collagen fibrils, microfibrils, and elastic fibres, embedded in hyaluronan and proteoglycans. [2] It also contains the hair follicles, sweat glands, sebaceous glands, apocrine glands, lymphatic vessels and blood vessels which provide nourishment and waste removal from its own cells as well as for the epidermis.[3] Drugs that cross the highly impermeable outer layer, stratum corneum barrier, can diffuse to deeper capillaries for systemic distribution. To increase transdermal delivery, it must be emphasized disruption of stratum corneum microstructure using chemical or physical methods. Previous studies have emphasized either long exposures at moderate temperatures or very short exposures at high temperatures increases the skin permeability. [4]

Although hair cosmetics are widely available, the medical literatures in their hygienic impacts are rather scarce, and the specialized literatures are not readily 
accessible. However, it is well reported that all of protein treatment products contain formaldehyde and/or formaldehyde-producing ingredients. It is assumed that, the formaldehyde-free hair-smoothing products contain ingredients that turn into formaldehyde when they break down during the heat application. Ingredients that are interchangeable for or that break down of formaldehyde can include formalin, formic aldehyde, methanol, methylene glycol, methylene oxide, oxomethane and oxymethylene and others. Formaldehyde can cause irritation of the skin and long-term exposure can induce cancer particularly leukemia.[5,6]

Depending on the previous considerations, the present work searching the risks of using protein cosmetic treatment on rat's skin hygiene. The effects of hot air and /or $\gamma$ - irradiation after applying these products were, also, studied. Biochemical analyses and histopathological examinations were performed for determining the health consequences due to one of the mostly used protein conditioner in Egypt.

\section{EXPERIMENTAL WORK}

Ninety six adult albino rats, 48 males and 48 females, weighting $200 \pm 10 \mathrm{~g}$ were used in this study. They were supplied by the Animal House Laboratory, Nuclear Research Centre (NRC), Egyptian Atomic Energy Authority. They were housed under conventional conditions on sawdust free of toxic compounds. The mean ambient temperature in the housing facility was $28^{\circ} \mathrm{C}$ (range $26-$ $32^{\circ} \mathrm{C}$ ), and the mean relative humidity was $60 \%$ (range from $50-70 \%$ ) with12 hours light: 12 hours dark cycle. The animals were freely fed on a normal rodent pallets diet and clean water offered by ad-libitum throughout the whole experimental period.

\section{Ethical Clearance and Approval:}

Procedures involving animals and their care were conducted in conformity with international laws and policies. The rats were handled according to the International Guiding Principles for Biochemical Research Involving Animals -2012, and the experimental procedures were approved by the Research Ethics Committee of the National Centre for Radiation Research and Technology (REC-NCRRT), Egyptian Atomic Energy Authority.

The animals were divided into eight main groups; each group included 6 females and 6 males. The experimental groups designed as follows:

- Group 1: Rats were served as normal control group.

- Group 2: Rats were treated once with protein conditioner then attended to hot air.

- Group 3: Rats were treated with the hair conditioner once weekly for two weeks then attended to hot air post each treatment.
- Group 4: Rats were treated with the hair conditioner once weekly for three weeks then attended to hot air post each treatment.

- Group 5: Rats were received the treatment as the same manner as Group 2 and after one week, they were exposed to $10 \mathrm{~Gy} \gamma$-radiation.

- Group 6: Rats were received the treatment as the same manner as Group 3 and after one week, they were exposed to $10 \mathrm{~Gy} \gamma$-radiation.

- Group 7: Rats were received the treatment as the same manner as Group 4 and after one week, they were exposed to $10 \mathrm{~Gy} \gamma$-radiation.

- Group 8: Rats were treated with hair conditioner once and subjected to 10 Gy $\gamma$-radiation without exposure to hot air.

About half gram of high grade protein conditioner was used. It was applied on $\approx 3 \times 3 \mathrm{~cm}$ rat's dorsal area and rubbed for nearly $3 \mathrm{~min}$. The massaged place was exposed to hot dry air, from a blow dryer, for an additional one min. The measured temperature at the rubbed spot was about 95 ${ }^{\circ} \mathrm{C}$. A day after, animals were placed in ventilated special containers and subjected to 10 Gy single dose whole-body gamma radiation.

Irradiation was performed in gamma cell-40, National Centre for Radiation Research and Technology (NCRRT), Egypt, using cesium-137 as a $\gamma$ - source at $0.84 \mathrm{~Gy} / \mathrm{min}$ dose rate.

\section{Skin and blood samples collection:}

One week post-irradiation exposure, the rats were anesthetized and blood samples were drawn from orbital venous plexus and centrifuged for 10 minutes at 3000 rpm. The sera were separated and stored at $-20^{\circ} \mathrm{C}$ for biochemical analyses. Photos were taken to record the changes in morphological features of the treated skin area. Then, skin tissue samples $\approx 1 \times 1 \mathrm{~cm}^{2}$ were collected by cutting the centre part of the treated area and stored in $10 \%$ formalin for histopathological examinations.

\section{Biochemical analyses:}

The quantitative determination of collagen type I, (Col I), concentration $(\mathrm{pg} / \mathrm{ml})$ in the rats' sera was carried out following the sandwich enzyme immunoassay technique. (www.cusabio.com). Also, the vascular endothelial growth factor (VEGF) was assayed based on standard sandwich enzyme - linked immune - sorbent assay technology (www.bosterbio.com).On the other hand, inducible heat shock protein 70 (enzyme- linked immunosorbent assay) was detected and measured in pg/ml using HSP70 ELISA kit. (www.enzolifesciences.com).

\section{Histopathological examinations:}

Control and treated skin cuts from all groups, were taken and fixed in $10 \%$ formalin for $24 \mathrm{~h}$. They were washed with tap water, and then, for dehydration, with serial dilutions of alcohols (methyl, ethyl, and absolute ethyl). The specimens were cleared in xylene and 
embedded in paraffin at $56{ }^{\circ} \mathrm{C}$ in a hot air oven for $24 \mathrm{~h}$. Paraffin - bees wax tissue blocks were prepared for sectioning at $4 \mu \mathrm{m}$ with a sliding microtome. The tissue sections were collected on glass slides, de-paraffinzed, and then stained with haematoxylin and eosin, [7] and examined using light microscope.

\section{Statistical analysis:}

All values were expressed as mean \pm S.E. Statistical analysis was performed with one way analysis of variance (ANOVA) followed by Duncan's test using SPSS program. $\mathrm{P}$ values $<0.05$ were considered to be statistically significant.

\section{RESULTS}

Hair conditioners seem to be a catastrophic tool that increases the possibility of patient's alopecia and skin ulcerations which can end to cancer.

\section{Impacts of hot air and/or $\gamma$ irradiation post protein conditioner application on rats' morphological features:}

Some morphological signs due to the impact of hot air and /or gamma irradiation post the application of protein conditioner were observed in both male and female rats as ungroom hair, hair loss, alopecia, eczema and ulceration at the application region.( Fig. 1, (A) \& (B)).
A) Male
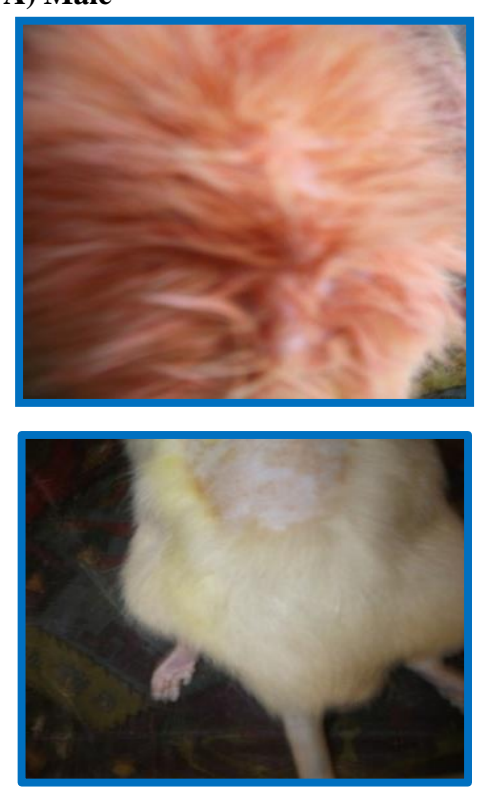

\section{B) Female}
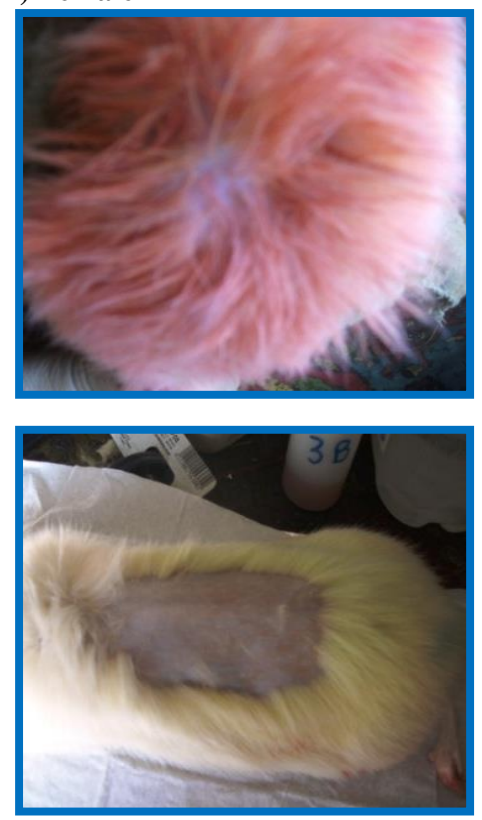
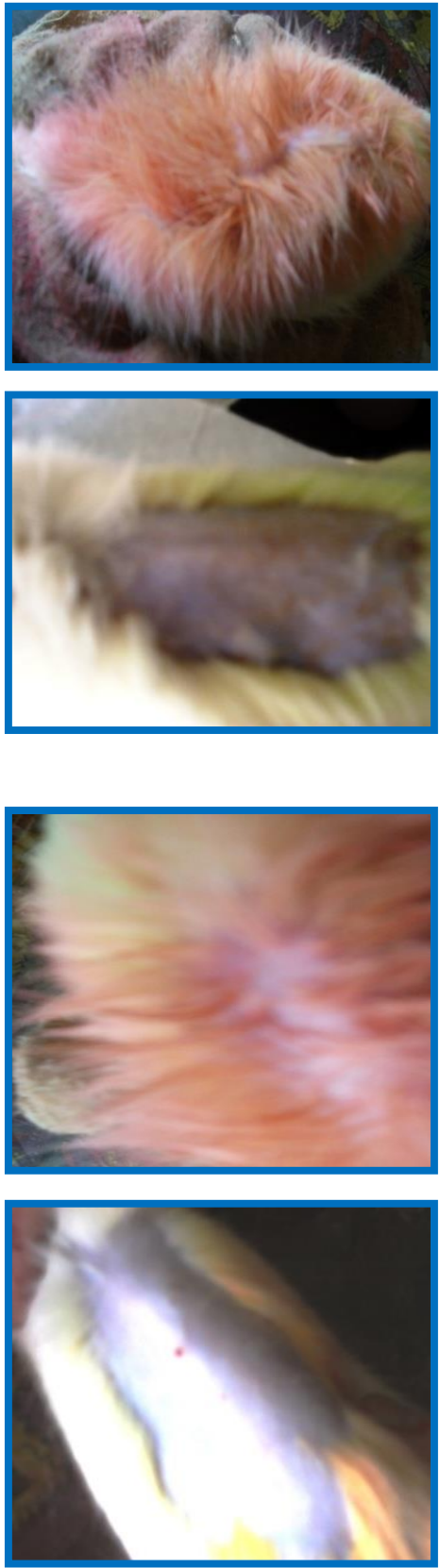
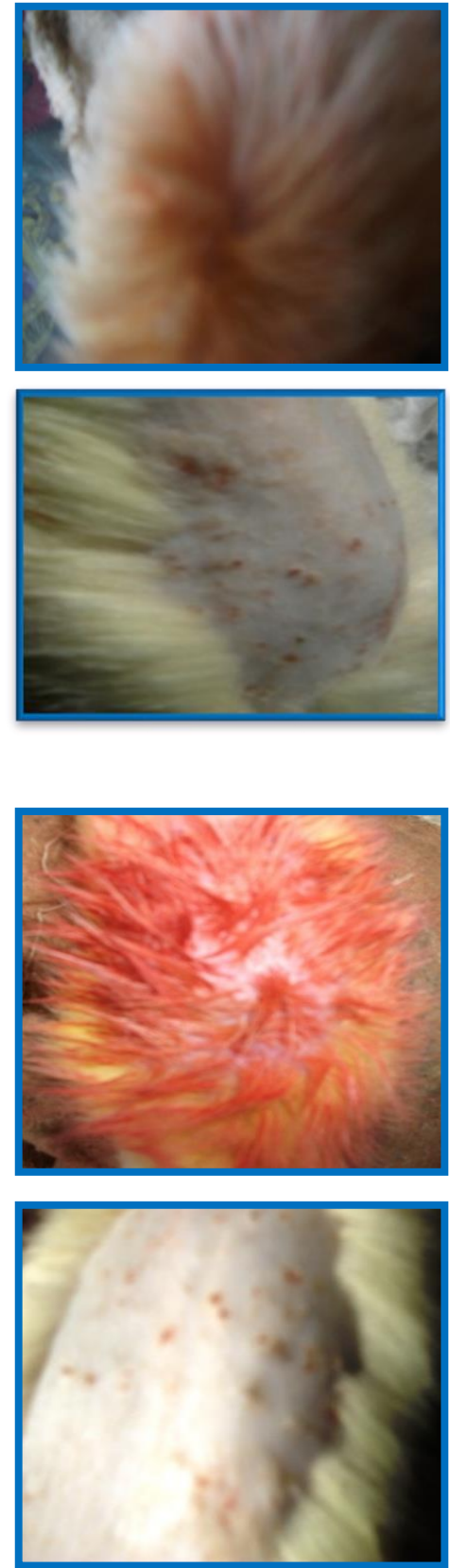

Fig. (1): Some morphological signs e.g. ungroom hair, hair loss, alopecia, eczema and ulcerations on a shaved dorsal treated area due to the protein conditioner applications then attended to hot air and / or irradiation treatment in male (A) and female (B) albino rats. 
It is clear from the figure that males were, morphologically, more susceptible than females for protein conditioner and the subsequent hot air and /or irradiation treatments.

The photographs were taken during the experimental work were focused on the treated shaven dorsal area of rats to demonstrate the impact of the frequent application of protein conditioner followed by hot air and/or gamma irradiation. The damage to hair was manifested by its ungroom, broken strands ended to their loss and alopecia, besides the clear appearance of skin ulcers ranging from eczema to sever erythemai.

\section{Biochemical Analyses:}

Table (1) revealed that, the male rats received protein conditioner once, twice or three times followed by hot air in each time showed significant decreases $(p<0.05)$ in Col I levels and significant increases in HSP70 as compared to the controls.

Table (1): Col I, HSP 70 and VEGF contents in male rats' sera post protein conditioner application then attended to hot air and/or gamma irradiation treatments.

\begin{tabular}{cccc}
\hline parameters & Col I $(\mathbf{p g} / \mathbf{m l})$ & HSP70 $(\mathbf{p g} / \mathbf{m l})$ & VEGF $(\mathbf{p g} / \mathbf{m l})$ \\
\hline Control & $760.18^{\mathrm{a}} \pm 1.12$ & $13.06^{\mathrm{a}} \pm .0 .55$ & $105.44^{\mathrm{a}} \pm 0.61$ \\
$\mathrm{P}+\mathrm{H}$ once & $681.35^{\mathrm{a}} \pm 0.70$ & $16.59^{\mathrm{a}} \pm .0 .44$ & $125.02^{\mathrm{b}} \pm 0.78$ \\
$\mathrm{P}+\mathrm{H}$ twice & $582.76^{\mathrm{b}} \pm 9.98$ & $17.92^{\mathrm{b}} \pm 0.36$ & $101.41^{\mathrm{a}} \pm 0.66$ \\
$\mathrm{P}+\mathrm{H}$ triple & $556.32^{\mathrm{b}} \pm 2.29$ & $25.60^{\mathrm{b}} \pm .0 .32$ & $89.20^{\mathrm{b}} \pm 0.66$ \\
$\mathrm{P}+\mathrm{H}$ once $+\mathrm{R}$ & $601.63^{\mathrm{b}} \pm 0.62$ & $20.00^{\mathrm{b}} \pm 0.79$ & $121.21^{\mathrm{b}} \pm 0.76$ \\
$\mathrm{P}+\mathrm{H}$ twice $+\mathrm{R}$ & $523.37^{\mathrm{c}} \pm 1.27$ & $23.3 \mathrm{c} \pm .52$ & $98.34^{\mathrm{ab}} \pm 0.64$ \\
$\mathrm{P}+\mathrm{H}$ triple $+\mathrm{R}$ & $526.88^{\mathrm{c}} \pm 12.06$ & $25.20^{\mathrm{c}} \pm 0.03$ & $85.92^{\mathrm{b}} \pm 0.97$ \\
$\mathrm{P}+\mathrm{R}$ & $683.42^{\mathrm{b}} \pm 1.09$ & $23.61^{\mathrm{c}} \pm 0.62$ & $102.56^{\mathrm{a}} \pm 0.64$ \\
\hline
\end{tabular}

Col I= collagen type I; HSP 70 = heat shock protein 70;

$\boldsymbol{V E G F}=$ vascular endothelial growth factor

$\boldsymbol{P}=$ protein conditioner $\boldsymbol{H}=$ hot air $; \boldsymbol{R}=10$ Gy single

dose $\gamma$ - irradiation

Values represent means \pm S.E.

Values bearing different superscript in the same column are statistically different.

The reductions in Col I concentrations- were dependent on repetition of the treatments. All treated male animal groups, exposed to 10 Gy single dose gamma radiation, either, after attending hot air post the application of protein conditioner, or exposed only to $\gamma$-rays showed significant $(\mathrm{p}<0.05)$ decreases in collagen type I contents but highly significant escalation in HSP70 concentrations relative to the control ones. On the other hand, VEGF activities demonstrated inconsistence trends where, it showed slightly increases in males received protein conditioner for one time followed by either hot air or by hot air and $\gamma$ - irradiation compared to the control and other groups.

It is worth be notified that, males rats 'sera received only 10 Gy single dose $\gamma$ - rays, post protein conditioner application presented more than $44 \%$ increase in HSP70 contents but $\approx 10 \%$ and less than $3 \%$ decreases in Col I \& VEGF concentrations, respectively. Table (1).

As shown in table (2), in female rats the repeated exposures to protein conditioner followed by-hot air had a detrimental effect as evidenced by a significant $(\mathrm{p}<0.05)$ decreases in collagen and increase in HSP70 levels as compared to the controls. These behaviours were remarkably depended on the repetition of exposure treatment.

It is important to mentioning that; exposure to hot air followed by gamma irradiation post application of protein conditioner had the strongest influence on HSP70 contents at all. On the other hand, VEGF activities demonstrated inconsistence trends where, it showed slightly increases in females received protein conditioner for one time followed by hot air only or by hot air then to $\gamma$-irradiation compared to the control and other groups. Whereas the females groups received protein conditioner twice or three times then attended to hot air or to hot air and irradiation showed non- significant decreases in VEGF contents. It should be notified that rats 'sera for the -females received only 10 Gy single dose $\gamma$ - rays, post protein conditioner application presented more than $13 \%$ increase in HSP70 contents but $\approx 10 \%$ and less than $5 \%$ decreases in Col I \& VEGF concentrations, respectively. Table (2).

Table (2): Col I, HSP 70 and VEGF contents in female rats' sera post protein conditioner application then attended to hot air and/or gamma irradiation treatments.

\begin{tabular}{|c|c|c|c|}
\hline Groups & Col I. (pg/ml) & HSP70 (pg/ml) & VEGF (pg/ml) \\
\hline Control & & $11.42^{\mathrm{a}} \pm 0.26$ & $110.32^{\mathrm{a}} \pm 1.21$ \\
\hline $\mathrm{P}+\mathrm{H}$ once & $664.05^{\mathrm{b}} \pm 6.22$ & $16.50^{\mathrm{b}} \pm 1.22$ & $118.37^{\mathrm{a}} \pm 1.25$ \\
\hline $\mathrm{P}+\mathrm{H}$ twice & & & \\
\hline $\mathrm{P}+\mathrm{H}$ triple & $377.73^{\mathrm{d}} \pm 16.06$ & $27.60^{c} \pm 0.82$ & $93.75^{\mathrm{b}} \pm 0.31$ \\
\hline $\mathrm{P}+\mathrm{H}$ once $+\mathrm{R}$ & $561.25^{\mathrm{c}} \pm 11.12$ & $21.22^{\mathrm{d}} \pm 0.47$ & $114.13^{a} \pm 0.76$ \\
\hline $\mathrm{P}+\mathrm{H}$ twice $+\mathrm{R}$ & $514.77^{\mathrm{c}} \pm 0.40$ & $21.91^{\mathrm{d}} \pm 0.27$ & $92.70^{\mathrm{b}} \pm 0.27$ \\
\hline $\mathrm{P}+\mathrm{H}$ triple $+\mathrm{R}$ & $474.95^{\mathrm{d}} \pm 1.32$ & $29.70^{c} \pm 1.16$ & $90.89^{b} \pm 0.29$ \\
\hline$P+R$ & $669.89^{\mathrm{b}} \pm 3.14$ & $26.56^{\mathrm{c}} \pm 0.07$ & $105.30^{\mathrm{a}} \pm 0.5$ \\
\hline
\end{tabular}

Col I= collagen type I; HSP 70 = heat shock protein 70;

$\boldsymbol{V E G F}=$ vascular endothelial growth factor

$\boldsymbol{P}=$ protein conditioner $\boldsymbol{H}=$ hot air $; \boldsymbol{R}=10$ Gy single dose $\gamma$ irradiation

Values represent means \pm S.E.

Values bearing different superscript in the same column are statistically different 
On the other hand, there were no significant differences in collagen levels between the females subjected to protein conditioner followed by hot air once and those exposed to irradiation only post protein conditioner application. The activity of VEGF showed slightly increases in females received protein conditioner once followed by either hot air or hot air and radiation treatment. Yet, VEGF contents were decreased in females receiving protein twice and three times and treated either with hot air or hot air plus irradiation.

Figure (2) described the percent changes, relative to the controls, in biochemical concentrations of Col I [A], HSP70 [B] and VEGF [C] for males and females rats' sera under various treatments. It was noticed that repeated usage of protein conditioner followed by hot air-it was more effective on collagen levels in females than males. While exposure to 10 Gy of $\gamma$-irradiation didn't represent noticeable difference in $\mathrm{Col}-1$ percentages between males and females rats. In contrary, irradiation with 10Gy intensified the effect of protein conditioner application post hot air on Col-1 and this effect was greater in females with repeated treatment by more than $35 \%$ matched to male. It should be notified that, the changes in concentration percentages of HSP70 in males relative to females tracked the same trends as Col 1. Regarding to VEGF trend, it was noticed that, hot air post protein conditioner application was higher in males than in females, whereas irradiation exposure did not represent marked changes in either groups.

\section{Histopathological Features:}

Histopathological observation is providing valuable necessary support data to indicate alterations in skin histology.
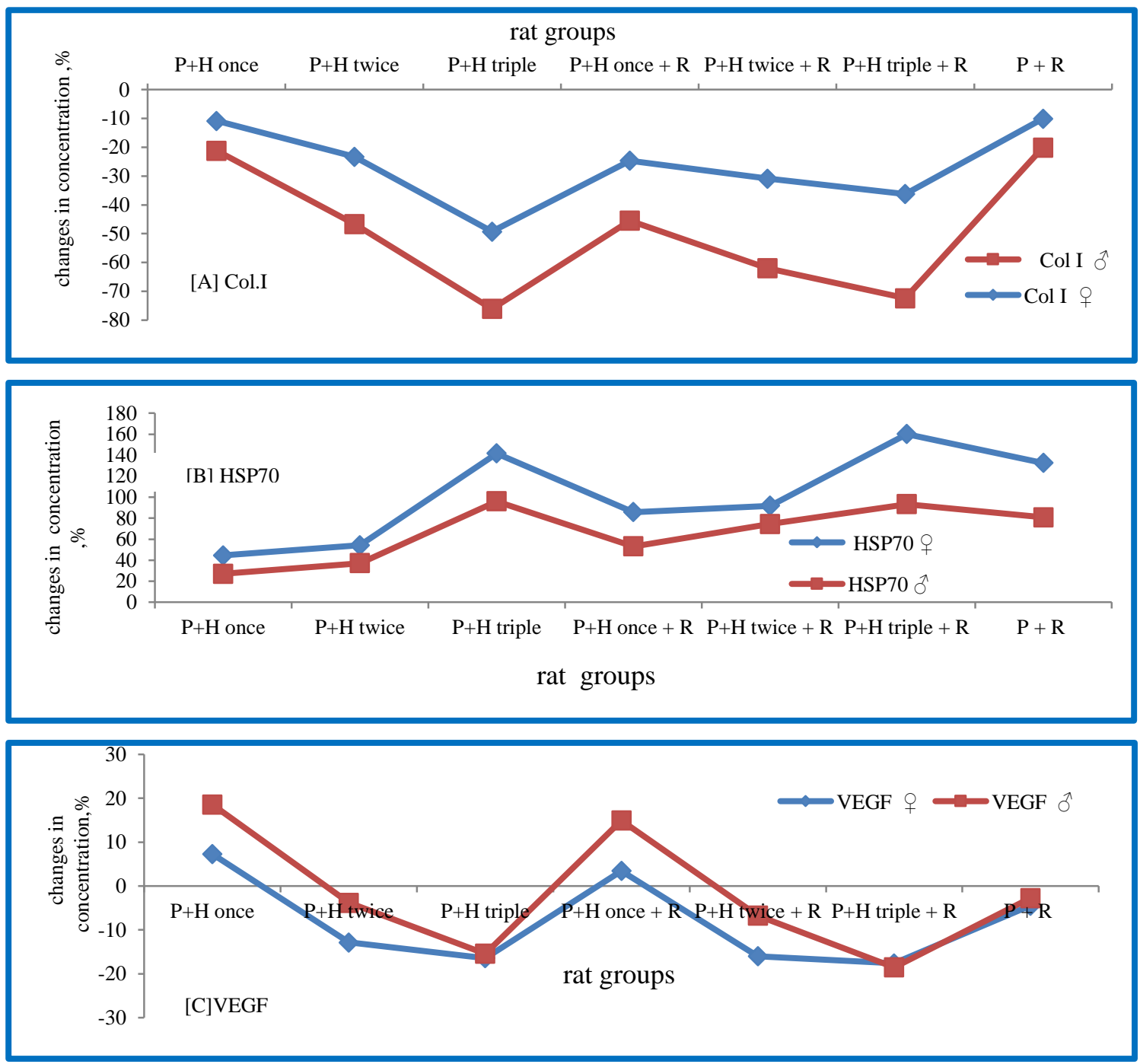

Fig. (2): changes in serum contents, in percent, of Col.- 1 [A], HSP70 [B] and VEGF [C] for female and male rats under various treatments. Col- I= collagen type I; HSP $70=$ heat shock protein 70; VEGF=vascular endothelial growth factor $P=$ protein conditioner; $H=$ hot air; $R=10$ Gy single dose $\gamma$-irradiation 


\section{Male rats' Skin Histopathological Features:}

\section{Control group:}

There was no histopathological alteration in the male rat skin architectures as recorded in Figure 3, (A \&B).

\section{Male rats exposed to one time protein conditioner application followed by hot air:}

There was focal acanthosis in the prickle cell layer of the epidermis and hyperkeratosis of the corium in association with migration of some of the hypertrophied

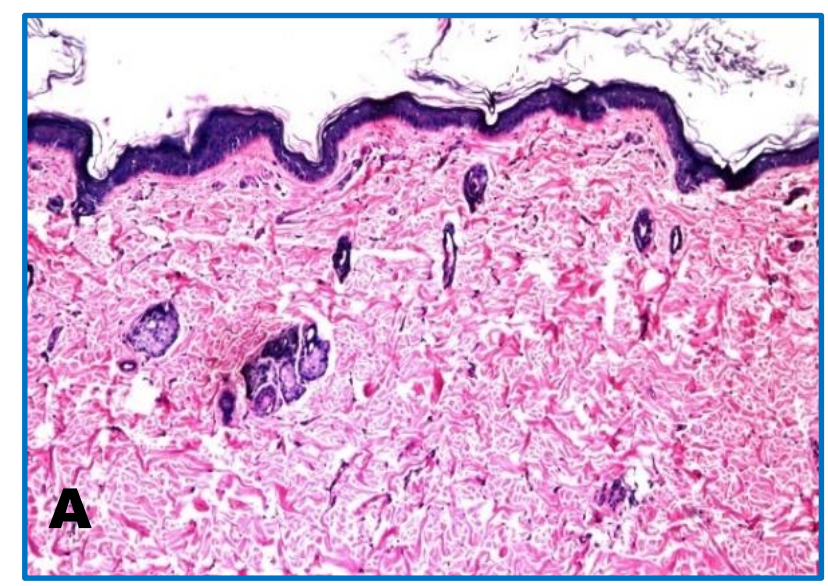

$H \& E, x 16$ hair follicles to the underlying basal cell layer of the epidermis. (Fig.4, A, B \&C).

Male rats exposed two times to protein conditioner applications and then to hot air:

Acanthosis was observed in the prickle cell layer of the epidermis (Fig. 5 A\&B). The subcutaneous tissue showed inflammatory cells infiltration with fibroblastic cells proliferation and newly formed blood capillaries (Fig.5 C \&D). The inflammatory cells infiltration and fibrosis were extended deep in between the degenerated skeletal musculature (Fig.5 E).

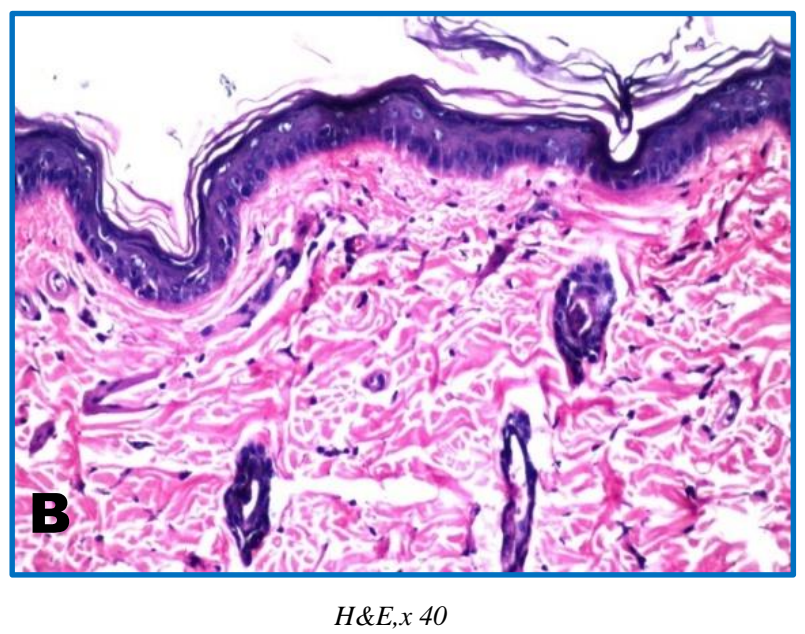

Fig. (3): Histological vertical section in the skin cut of the control male rat groups.

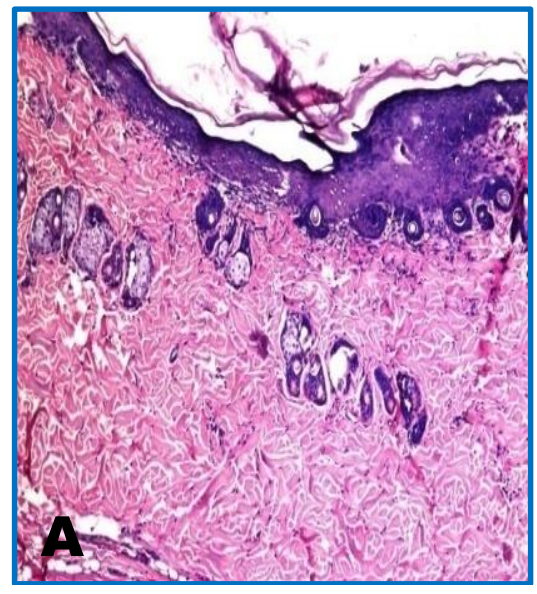

$H \& E, x 16$

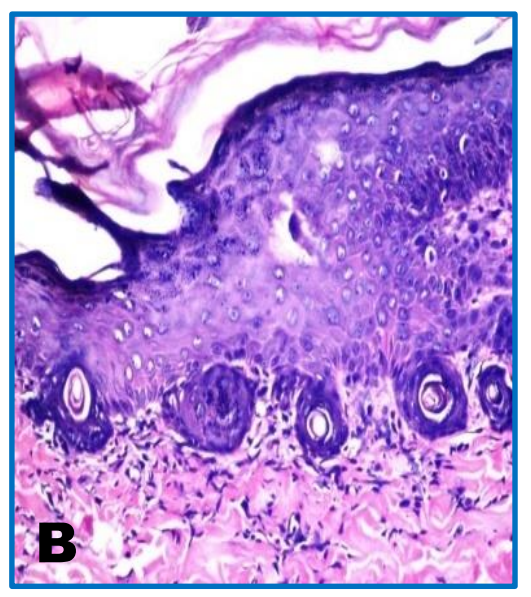

$H \& E, x 40$

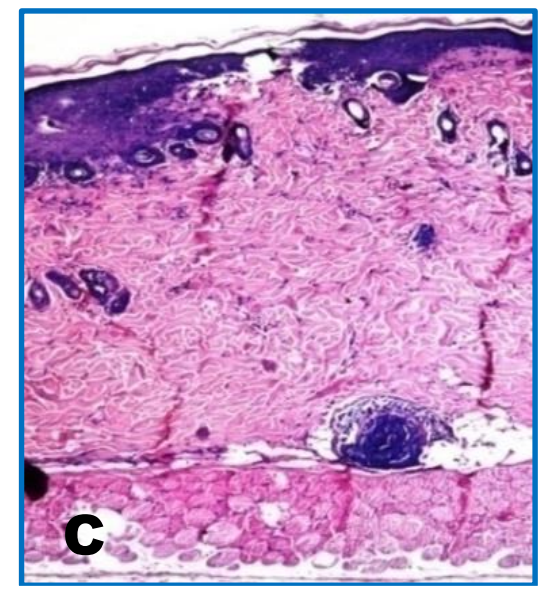

$H \& E, x 16$

Fig. (4): Histological sections for skin of male rat groups subjected to protein application one time then intended to hot air. 
Male rats exposed three times to protein conditioner applications then to hot air:

There was acanthosis in the prickle cell layer of the epidermis, (Fig.6, A), associated with migration of the hypertrophied hair follicles deep to the musculature. (Fig.6,B). The subcutaneous tissue showed fibrosis with newly formed blood capillaries (Fig.6, C \&D).
Male rats exposed to one time protein conditioner application and intended to hot air followed by $10 \mathrm{~Gy}$ single dose $\gamma$-rays:

Hyalinosis was observed in the acanthosis cells of the prickle layer in the epidermis (Fig.7, A\&B). The hyalinosis was observed also in the dermal layer underneath the acanthosis of the epidermis (Fig.7, C)
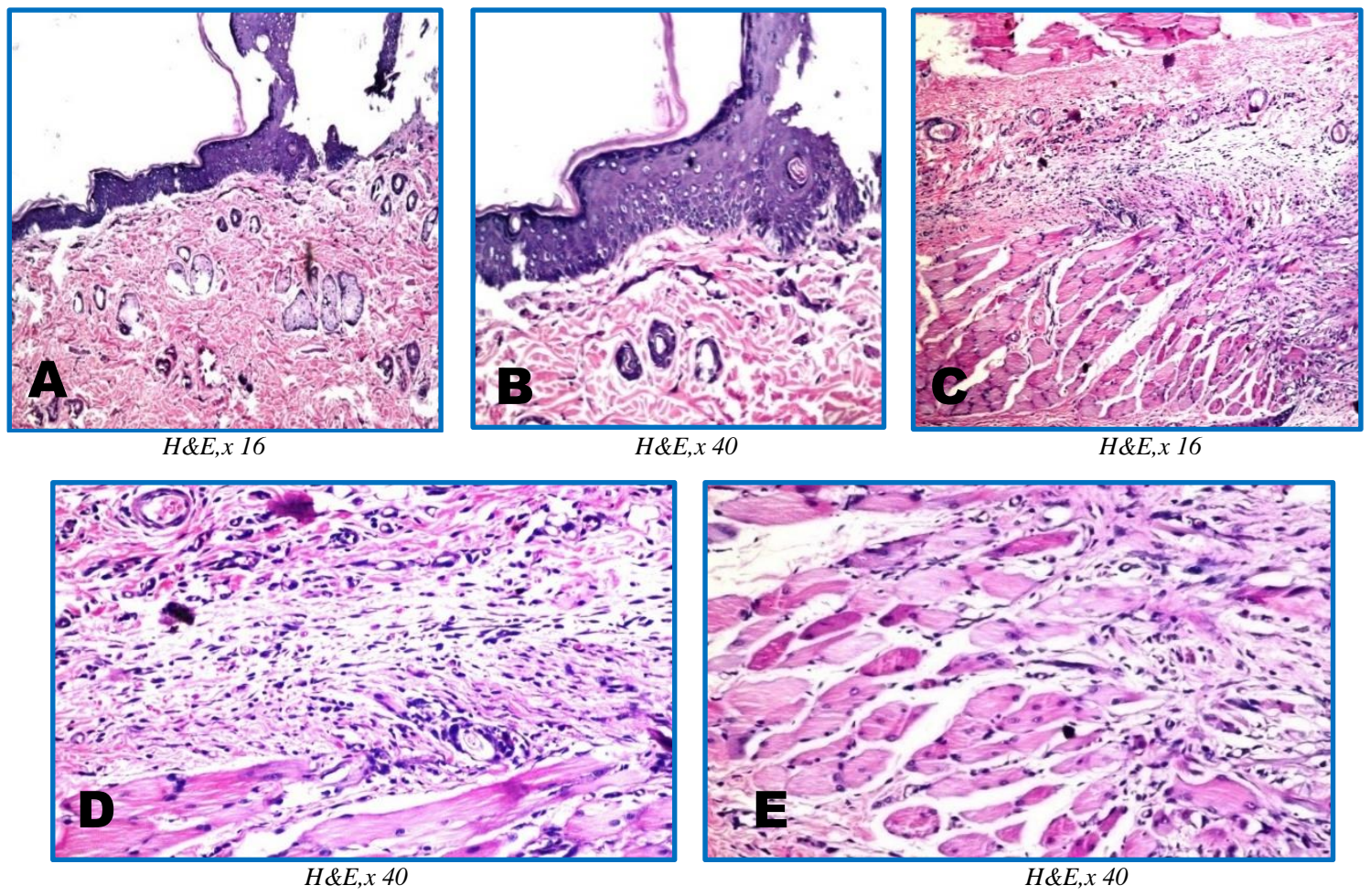

Fig. (5): Histological vertical section in the skin cut of the male rat groups exposed two times to protein conditioner applications and then to hot air.

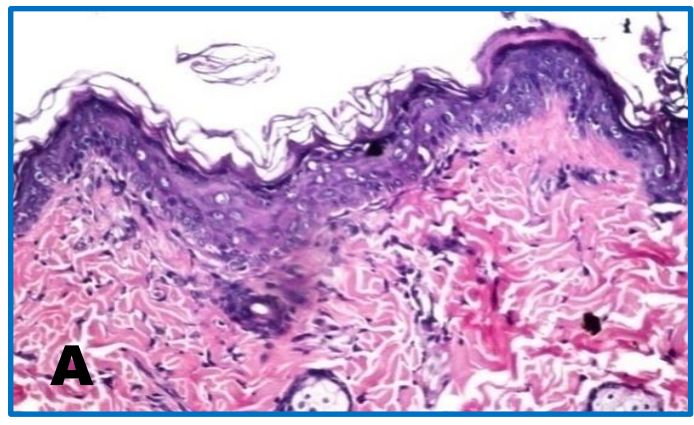

$H \& E, x 10$

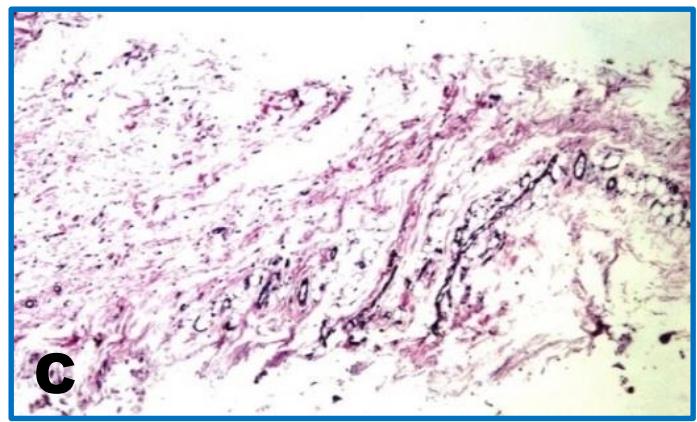

$H \& E, x 16$

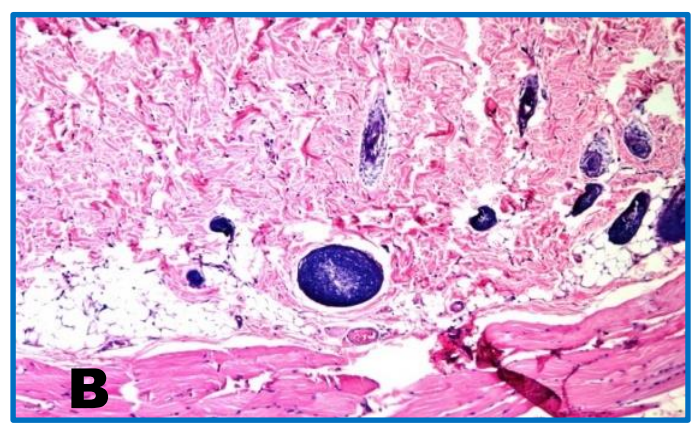

$H \& E, x 4$

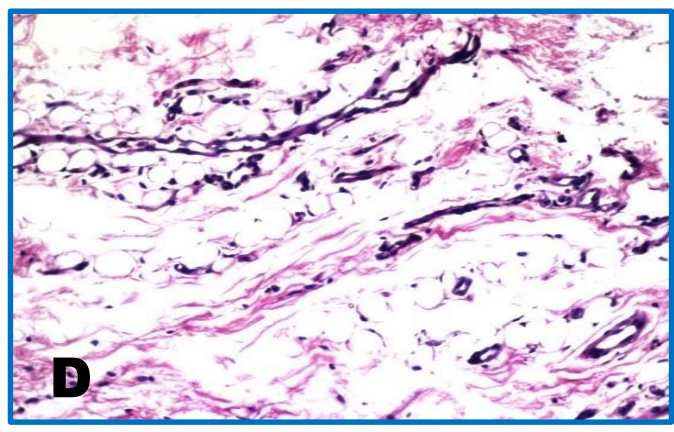

$H \& E, x 4$

Fig. (6): Histological sections for skin of male rat groups subjected to protein application three times then intended to hot air. 
Rats exposed to two times of protein conditioner application intended to and hot air followed by $10 \mathrm{G}$ single dose $\boldsymbol{\gamma}$ - irradiation:

Focal ulceration and necrosis were detected in the epidermis (Fig. 8, A\&B) associated with inflammatory

cells infiltration and congestion in the blood vessels at the deep dermis and subcutaneous tissue (Fig.8 C \&D).

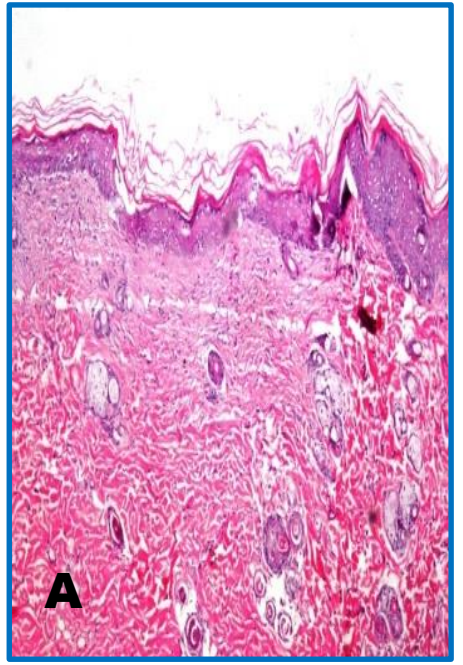

$H \& E, x 16$

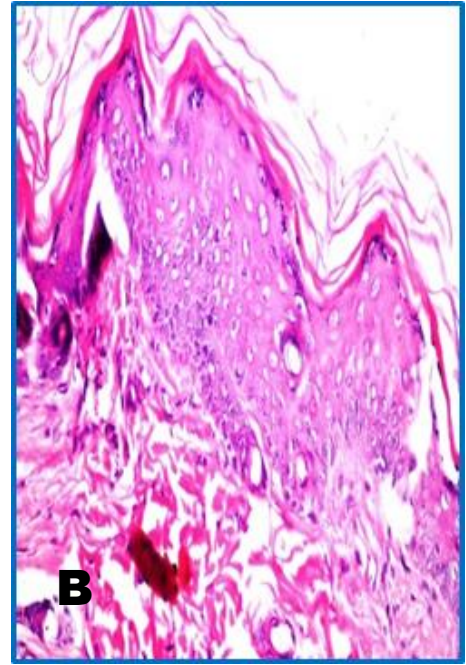

$H \& E, x 40$

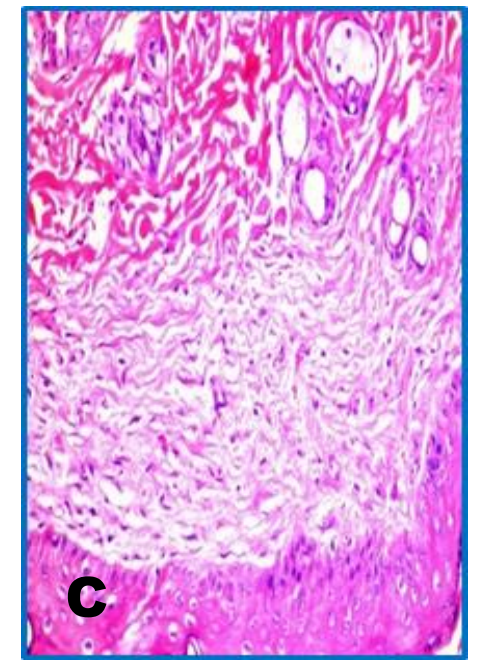

$H \& E, x 40$

Fig. (7): Histological vertical section in the skin cut of the male rat groups exposed to protein conditioner one time application and then to hot air followed by $10 \mathrm{~Gy}$ single dose $\gamma$-rays.

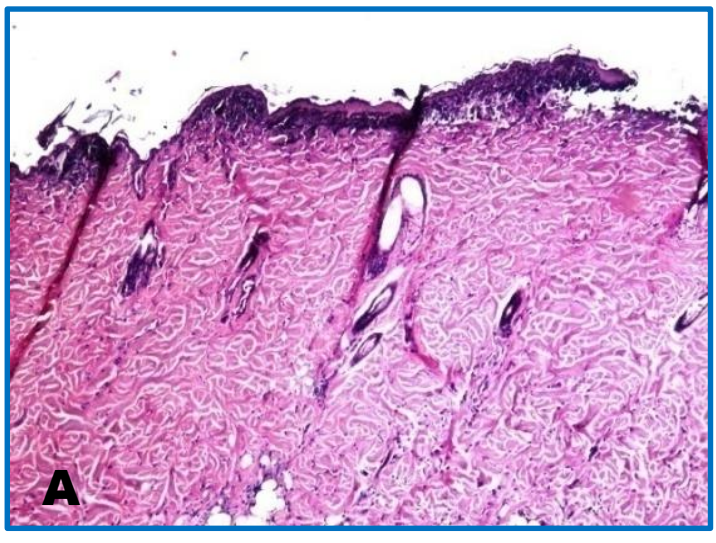

$H \& E, x 16$

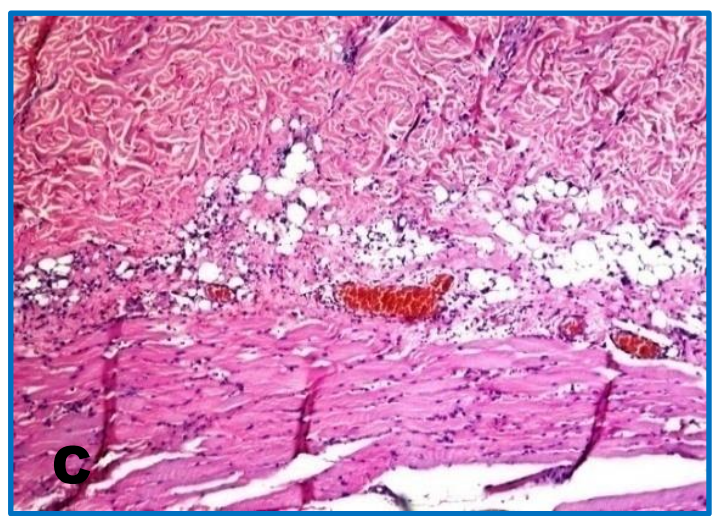

$H \& E, x 16$
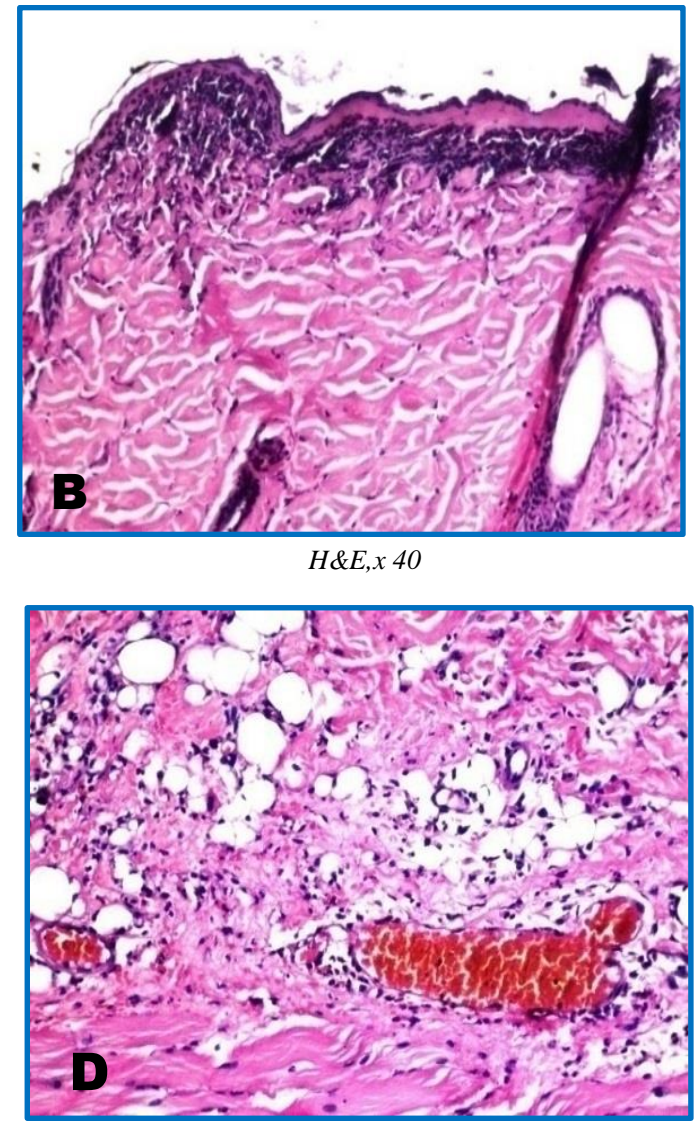

$H \& E, x 40$

Fig. (8): Histological sections for skin of male rat groups subjected to protein application two times then intended to hot air followed by $10 \mathrm{~Gy}$ single dose $\gamma$ - rays. 
Male rats exposed to three times protein conditioner application then intended to hot air followed by 10 Gy single dose $\gamma$-rays

The epidermis and dermis showed wide and deep focal area of ulceration and necrosis (Fig.9 A \& B). Inflammatory cells infiltration and fibrosis were detected in

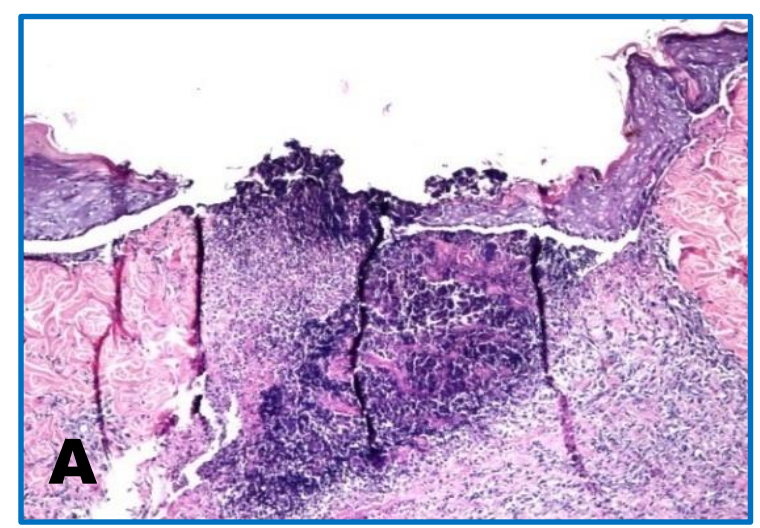

$H \& E, x 16$

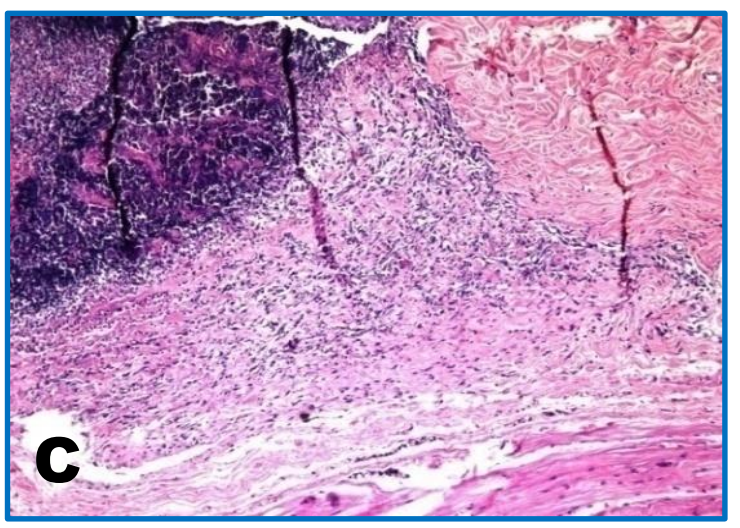

$H \& E, x 16$ the subcutaneous tissue as well as in between the skeletal muscle bundles (Fig.9 C \&D).

Male rats exposed to protein conditioner application followed by10 Gy single dose $\gamma$ - irradiation:

The epidermis showed acanthosis in the prickle cell layer and hyperkeratosis in the corium. (Fig.10 A \& B).

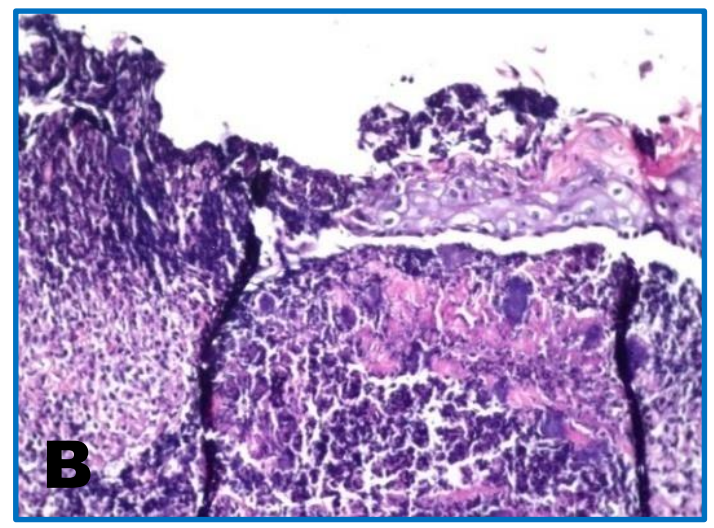

$H \& E, x 40$

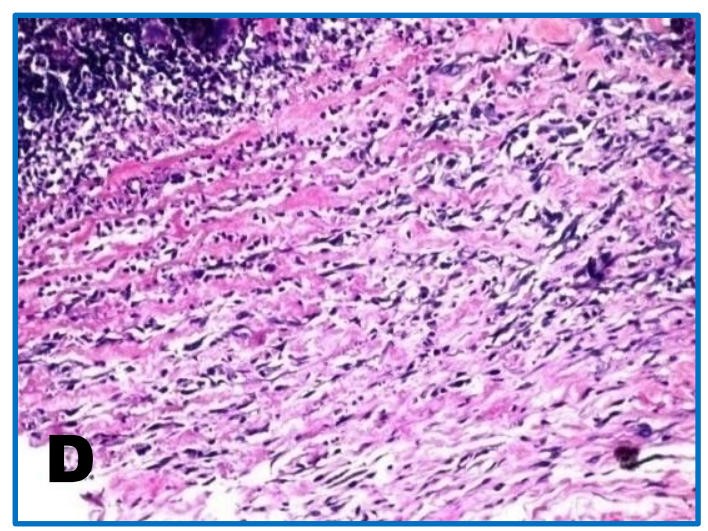

$H \& E, x 40$

Fig. (9): Histological vertical section in the skin cut of the male rat groups exposed to protein conditioner application three times and then to hot air followed by $10 \mathrm{~Gy}$ single dose $\gamma$-rays.

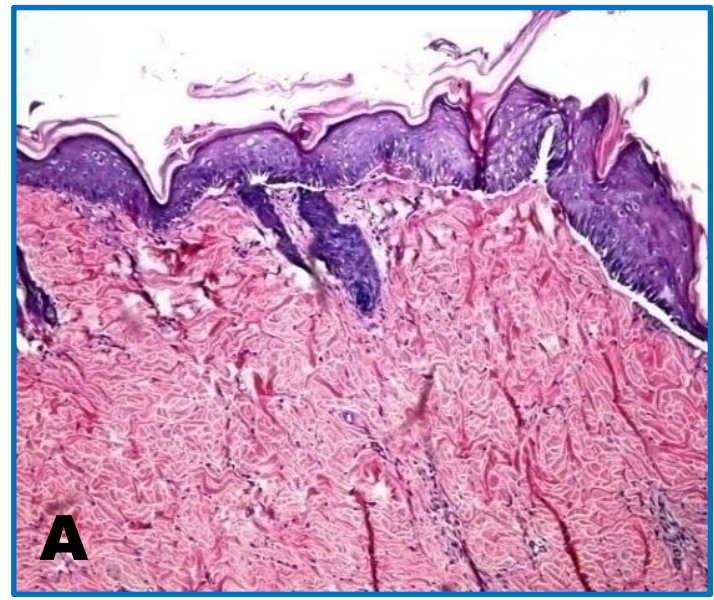

$H \& E, x 16$

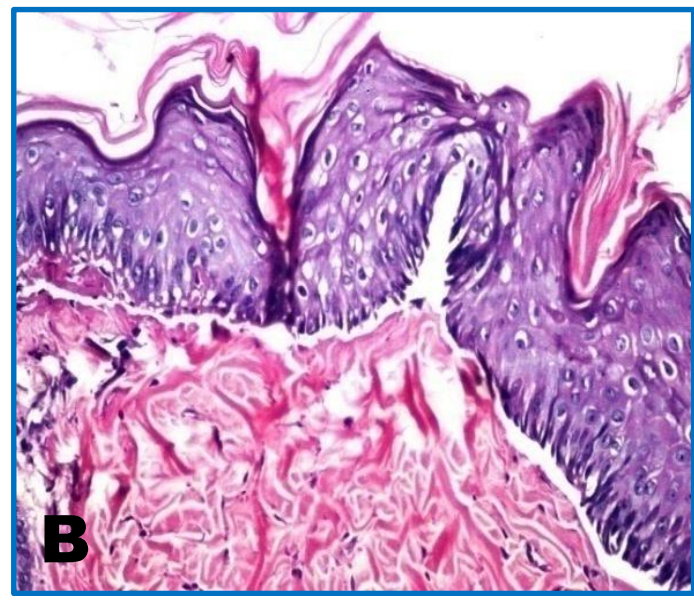

$H \& E, x 40$

Fig. (10): Histological vertical section in the skin cut of the male rat groups exposed to a protein conditioner application followed by 10 Gy single dose $\gamma$-rays. 


\section{Female Rats' Skin Histopathological Features:}

\section{Control group:}

There was no histopathological alteration and normal architectonic structure of the epidermis, dermis with sebaceous glands and hair follicles besides the underlying subcutaneous tissue as well as musculature were recorded in Figure 11, ( A \&B).

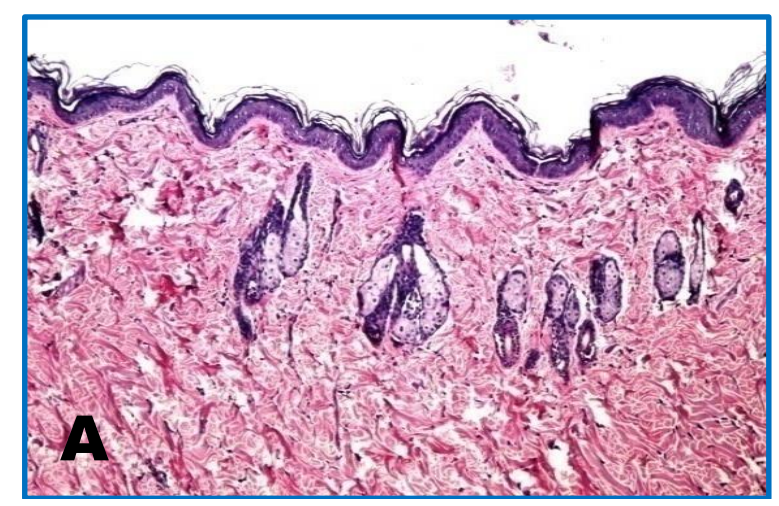

$H \& E, x 16$
Female rats exposed to one time protein conditioner application then intended to hot air

There was no histopathological alteration compared to the control ones as recorded in Figure .12, (A \&B).

Female rats exposed to two times protein conditioner applications followed by hot air:

There were no histopathological alterations compared to the untreated female group as recorded in Figure 13, (A \&B).

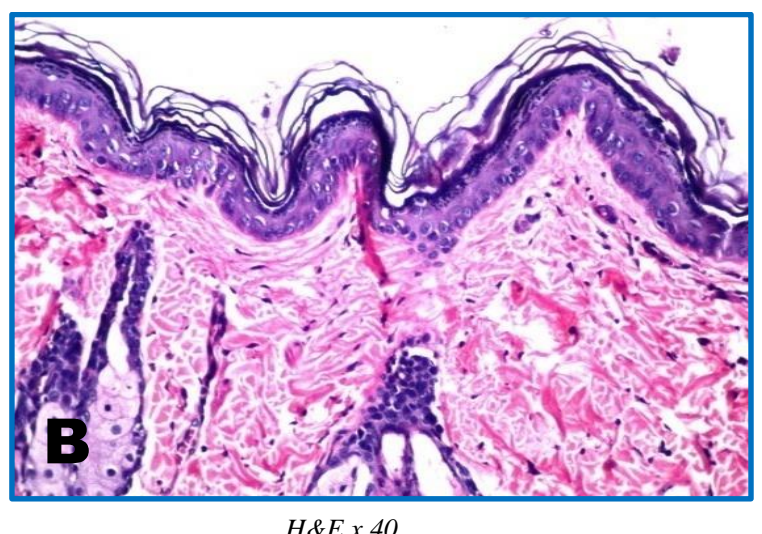

Fig. (11): Histological sections for skin of control femal rat groups.

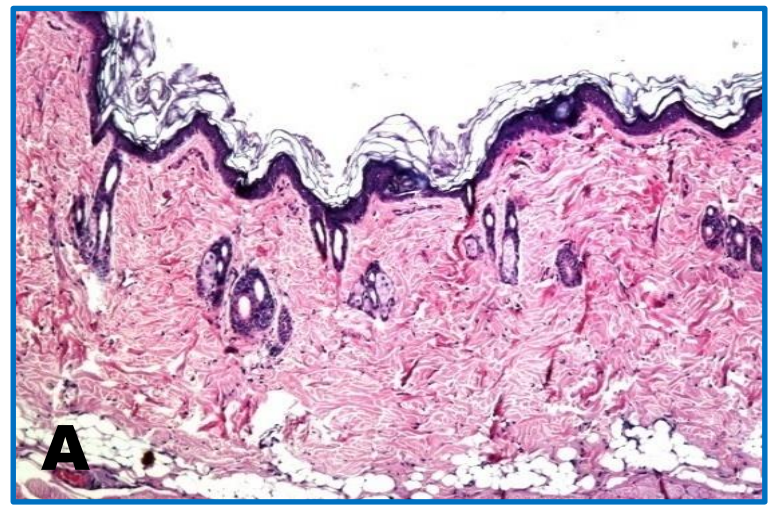

$H \& E, x 16$

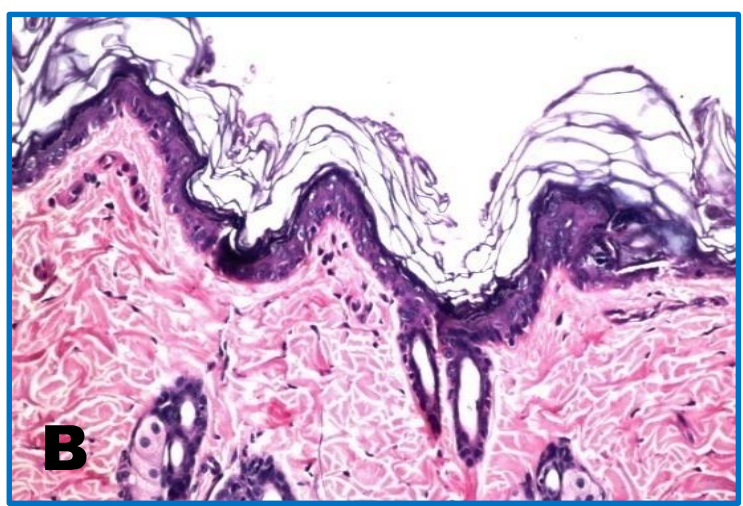

$H \& E, x 40$

Fig. (12): Histological vertical section in the skin cut of the female rat groups exposed one time to protein conditioner application and then to hot air.

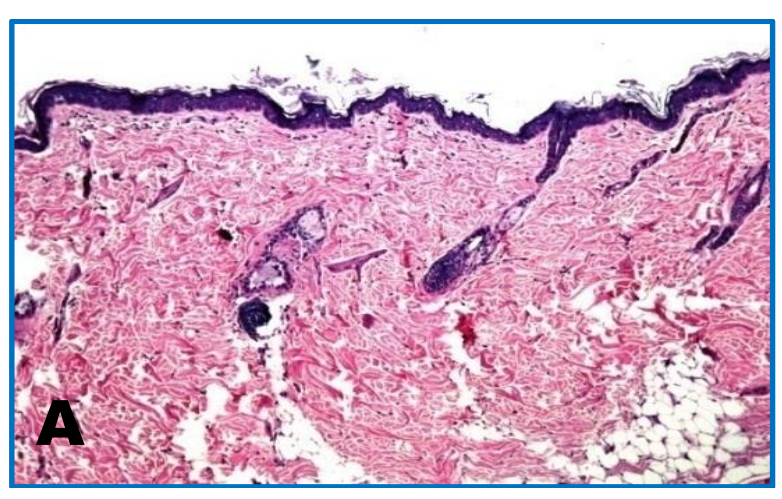

$H \& E, x 16$

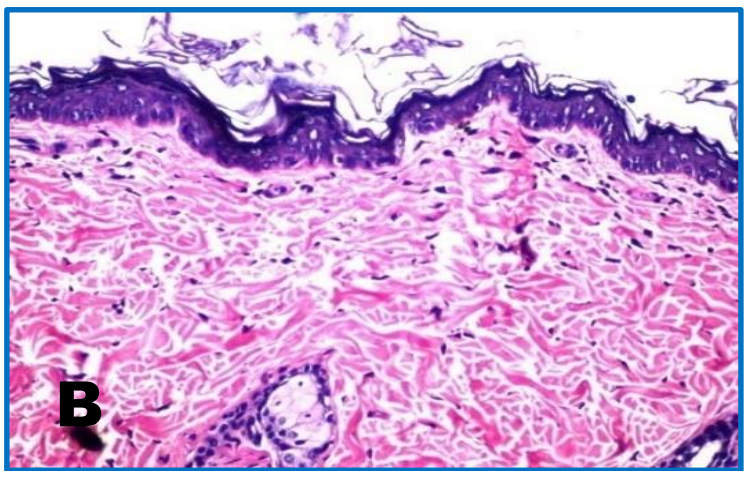

$H \& E, x 40$

Fig. (13): Histological sections for skin of femal rat groups exposed to two times protein conditioner applications followed by hot air. 
Femal rats exposed to three times of protein conditioner applications then intended to hot air:

Focal acanthosis was detected in the prickle cell layer of the epidermis associated with mild hyperkeratosis and polyps' formation as well as multiple wrinkling (Fig.14 A \& B).

Femal rats exposed to one time protein conditioner application then intended to hot air followed by $\mathbf{1 0}$ Gy single dose $\boldsymbol{\gamma}$-rays:

There was wide focal area of acanthosis in the prickle cell layer of the epidermis as well as hyper keratosis in

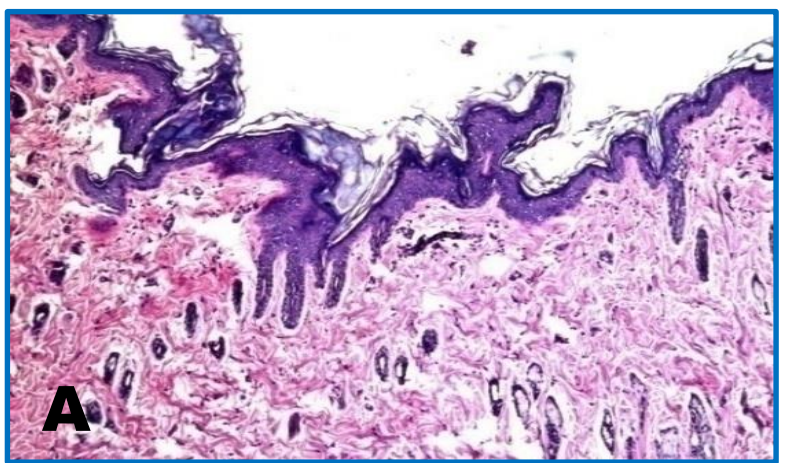

$H \& E, x 16$ association with fibroblastic cell proliferation in the underlying dermis.(Fig.15 A\& B).

Femal rats exposed to two times protein conditioner application then intended to hot air followed by 10 Gy single dose $\boldsymbol{\gamma}$-rays:

Acanthosis was detected in focal manner at the prickle cell layer of the epidermis with hyperkeratosis leading to formation of coli flower like projections. (Fig.16, A\&B).

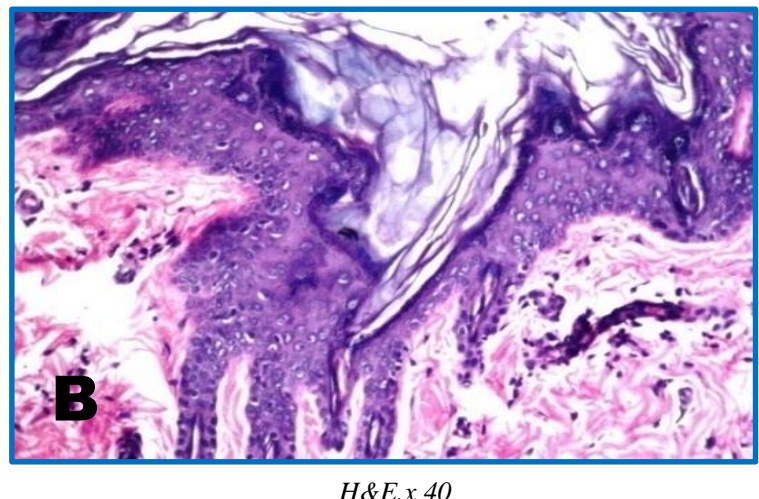

Fig. (14): Histological vertical section in the skin cut of the female rat groups exposed three times to protein conditioner applications then to hot air.

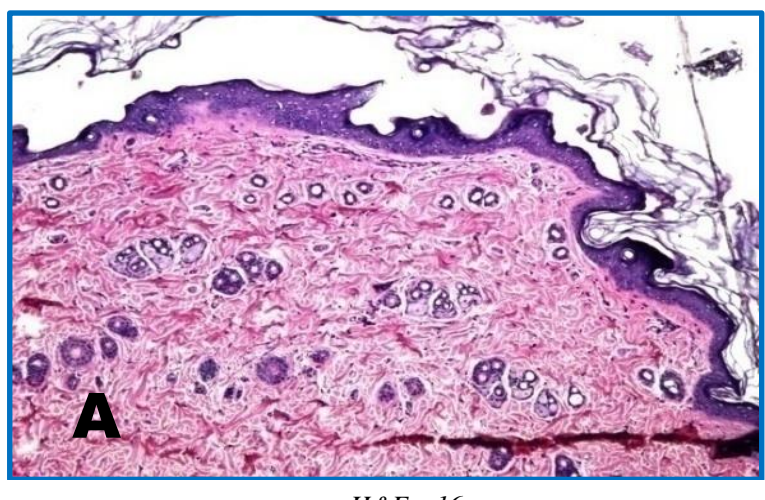

$H \& E, x 16$

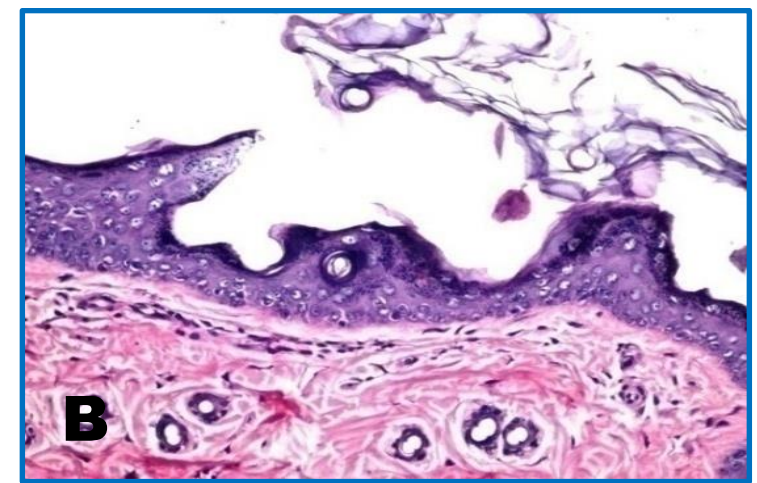

$H \& E, x 40$

Fig. (15): Histological sections for skin of femal rat groups exposed to one time protein conditioner application then intended to hot air followed by $10 \mathrm{~Gy}$ single dose $\gamma$-rays.

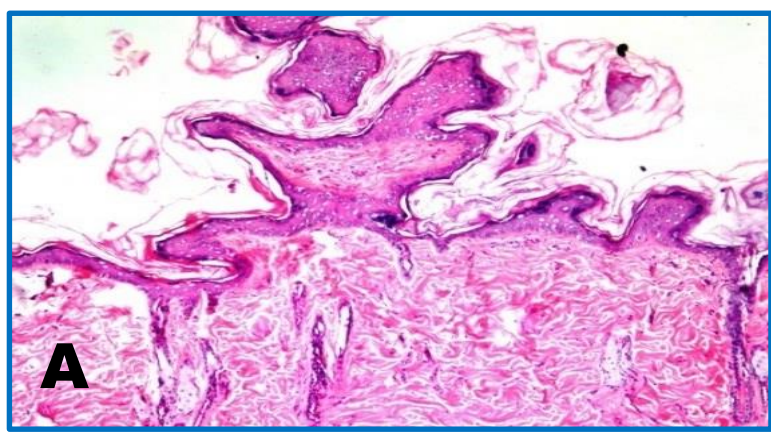

$H \& E, x 16$

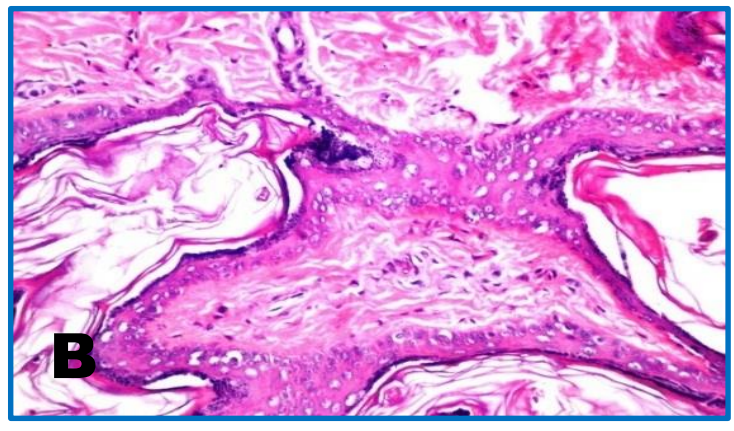

$H \& E, x 4$

Fig. (16): Histological vertical section in the skin cut of the female rat groups exposed two times to protein conditioner applications then to hot air followed by $10 \mathrm{~Gy}$ single dose $\gamma$-rays. 
Femal rats exposed to three times protein conditioner application then intended to hot air followed by 10 Gy single dose $\boldsymbol{\gamma}$-rays:

The epidermis showed atrophy in the cell layers with corrugation and more wrinkling while the underlying dermis had atrophy in the sebaceous glands as well as in the hair follicles. (Fig.17, A\& B).

Female rats exposed to protein conditioner application followed by10 Gy single dose $\gamma$ irradiation:

There was atrophy in the epidermal cell layer with focal acanthosis in few focal manners at the prickle cells and more wrinkling formation (Fig.18, A\&B).

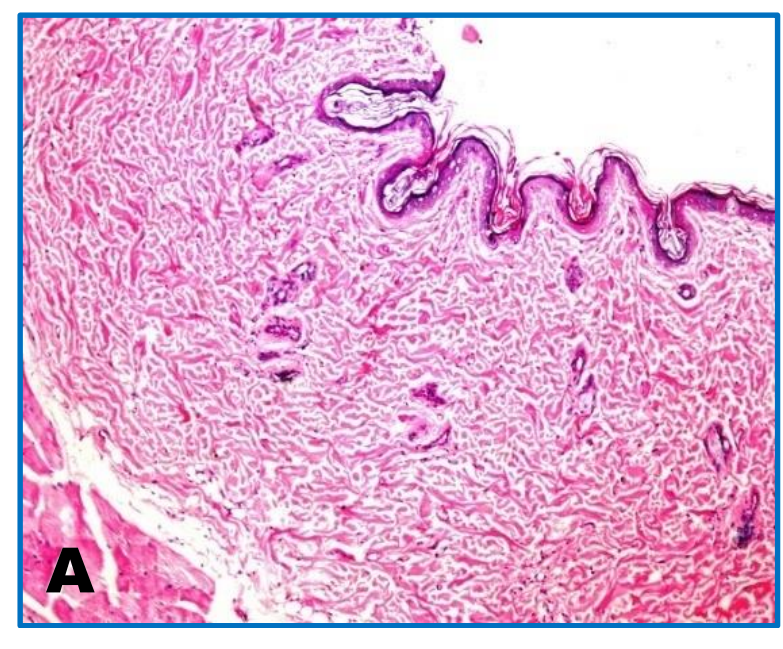

$H \& E, x 16$
It is clear from Table (3) that both genders were suffering from alterations in their skin ranging from sever focal ulceration and necrosis in epidermis and dermis, inflammatory reaction in subcutaneous tissue and degeneration of skeletal muscles in male rate to moderate wrinkling and atrophy in epidermis in femal rats. It is worth to notify that, the male rats were suffering from migration of hair follicles which can be a reason for alopecia symptoms appear post the various treatments.

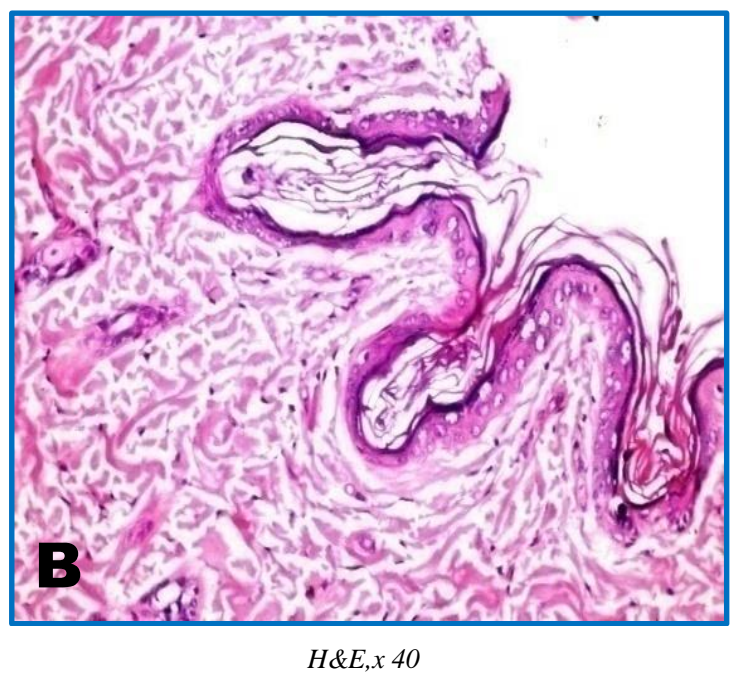

Fig. (17): Histological vertical section in the skin cut of the female rat groups exposed three times to protein conditioner applications then to hot air followed by $10 \mathrm{~Gy}$ single dose $\gamma$-rays

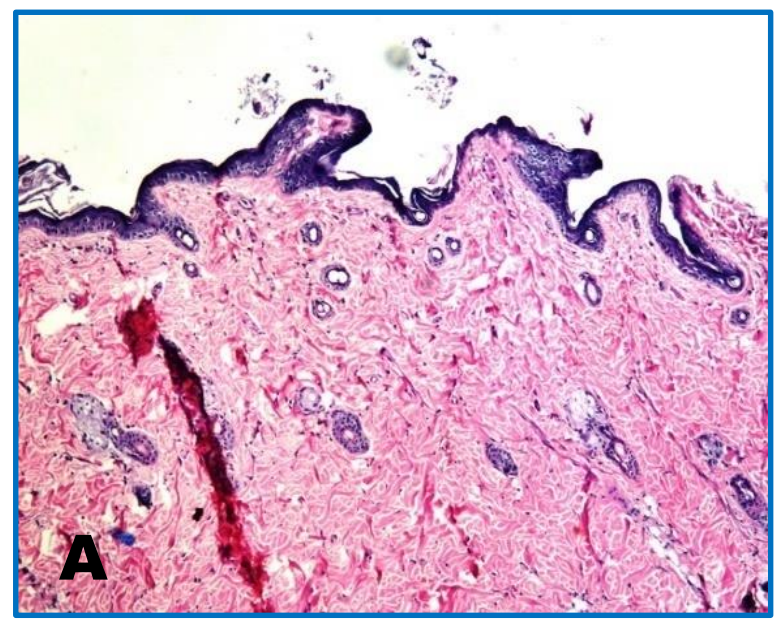

$H \& E, x 16$

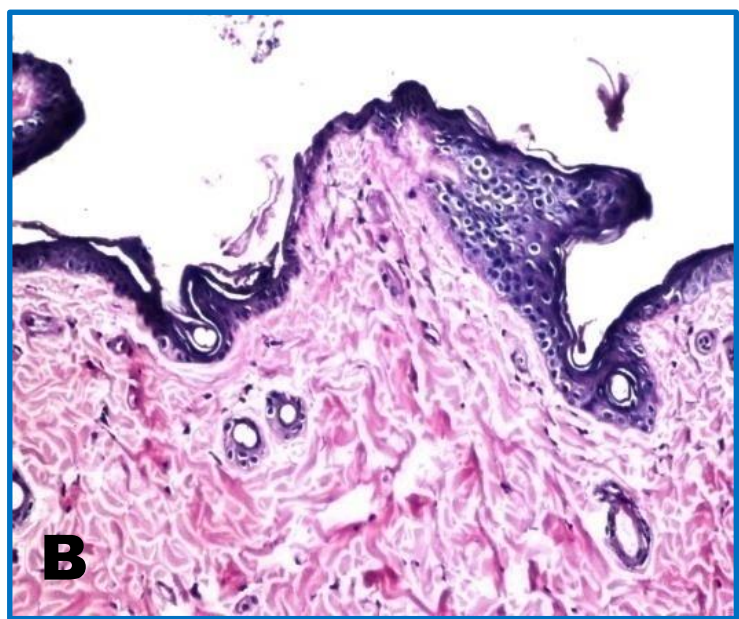

$H \& E, x 40$

Fig. (18): Histological sections for skin of femal rat groups subjected to a protein conditioner application followed by $10 \mathrm{~Gy}$ single dose $\gamma$-rays. 


\section{DISCUSSION}

Hair is an integrated system with a peculiar chemical and physical behaviour. Hair strands are complex biomaterials that derive the bulk of their properties from the keratin protein structures in the cuticle and cortex.

Thermal degradation of hair strands caused disruption of the three-dimensional hair structure due to water loss. Also, conformational changes in the protein induced by heat had adversely affect the strength, elasticity and texture of the hair. ${ }^{(8)}$ Hair damage may be also attributed to the presence of formaldehyde or its derivatives contained in protein conditioner.

Mazzei et al. [9] and Pierce at al. [10] reported that all hair smoothing treatments even those labeled "formaldehyde-free"-along with keratin contain formaldehyde or ingredients which can produce formaldehyde in situ when hair is heated.

Heat increases the skin permeability over a broad range of temperatures and durations, [4] and formaldehyde is quickly absorbed into the body through the affected skin .Even low level of formaldehyde can produce skin irritation, blisters, and dry flaky skin and react with the wool keratin to form cross-links with keratin amino acids [11] On the other hand, various abnormalities in the hair and hair follicles caused by radiation have been reported to be associated with structural re-arrangement and chemical modification in hair keratin. [12]

Damage due to the ionized gamma radiation is originated from the reaction of free radicals and direct deposition of energy. It has been demonstrated that exposure to ionizing gamma radiation cleaves the disulfide bonds and decomposes amino acids in keratin, cysteine hair leading to the formation of cysteic acid, $\mathrm{CySO}_{3}$ H.The numerous disulfide bonds formed by cysteine are responsible for the great stability of keratin and both keratin and cysteine are very reactive, can easily be reduced, oxidized, and hydrolyzed . [13] It is worth to mention that both of heat and irradiation produced decomposition of tryptophan residues to kynurenine type oxidation products. [14-16] Stress of heat and/or irradiation stimulated the pro-inflammatory cytokines, [17] which can further activate kynurenine pathway through the induction of indole amine 2, 3dioxygenase and tryptophan 2, 3-dioxygenase enzymes. The kynurenine pathway is responsible for over $90 \%$ of tryptophan degradation and linked to several diseases including cancer [18] Heat can generate $\mathrm{H}_{2} \mathrm{O}_{2}$ and $\mathrm{O}_{2}$, [19] through NADPH oxidase, xanthine oxidase, and the mitochondrial electron transport system. [20] Like heat, irradiation induces the formation of free radicals in cutaneous tissue which are responsible for up to $70 \%$ of damaging effect of ionizing radiation.[21] The damage by gamma rays for such specific target is less effective per amount of energy deposited but it can affect other targets in skin's keratin.

Van Lerberghe and Baeck, [22] described an acute oozing eczema of the scalp, forehead, and neck, and important oedema of the eyelids. The patient had performed a hair-smoothing treatment the day before, using a hair conditioner product.

The obtained data revealed that exposure to hot air and/or $\gamma$ - irradiation, post protein conditioner application, caused diminish in serum collagen and augmentation of HSP70 level referred to disorder in the biosynthesis and/or in skin protein structure that accounted for significant changes in the functional destabilization of skin. Exposure of the skin to ionizing irradiation decreases type I procollagen expression in vivo. On the other hand, HSP70 is constitutively expressed in specific skin cells, such as epidermal keratinocytes. HSP70 provides a natural barrier against potential environmental stressful attacks including heat and irradiation as a physiologic response to mediate repair mechanisms and reduce cellular damage. [23] Heat stress activates the heat shock response and accumulation of cytoprotective heat shock proteins (HSPs) which can preserve epithelial function and reduce systemic inflammation by inhibiting the NF- $\mathrm{kB}$ pathway of HSP70. [14] The changes in environment temperature can activate specific heat shock genes.[24]. Extracellular HSP70 can bind to receptors on professional antigen presenting cells and initiate the release of pro-inflammatory cytokines. [25-27] In addition, formaldehyde contained in the protein conditioner can be involved in the increase of HSP70 synthesis. [28]

The VEGF produced by a variety of cell types such as keratinocytes, mast cells, and macrophages in injured skin.[29] VEGF is well reported as an important proangiogenic molecule in the skin and acts as a strong positive regulator of angiogenesis and stimulates the endothelial cell functions required for the formation of new blood vessels. [30, 31] However, there is a contradiction of opinions about the effect of heat and irradiation on VEGF activity. Zhang et al., [32] Kim et 
al., [33] Chung and Eun, [34] and Lu et al., [35] reported that heat and irradiation, are important physical stimulus for angiogenesis indicating by VEGF activity. Irradiation exposure of skin is known to induce angiogenesis, i.e. Formation new blood vessels, in human skin. The newly formed vessels are immature and leaky, resulting in cutaneous inflammation by extravasations of inflammatory cells and by the inflammatory cytokines mediators produced by these cells. [36] These can contribute to further degradation of extracellular matrix proteins, providing an adverse, less permissive environment for the maintenance of normal vessel structure and function, leading to progressive loss of cutaneous vessels in skin. [34] On the other hand, Kim et al., [37] illustrated that HSP70 was considered a regulator of angiogenesis because it was tightly bound to the surface of vascular endothelial cells (VECs) and participated in extracellular signal-related kinasedependent angiogenesis. Another explanation based on that: nitrogen and oxygen reactive species are essential mediators for endothelial cells migration and VEGF- induced angiogenesis and can trigger the endothelial cell dysfunction. [38] It was demonstrated that Protein kinase $B$ mediates the VEGF-induced migration of endothelial cells via activation of endothelial nitric oxide (nitric oxide synthase). Inhibition of protein kinase B and endothelial nitric oxide phosphorylation by dominantnegative HSP subsequently reduces VEGF-stimulated migration of endothelial cells.

It should be notified that, the biological effect of UVradiation in dose range $10-20 \mathrm{~J} / \mathrm{m}^{2}$ can be significantly more damaging than of 7 or 10 Gy gamma irradiation. [39] Therefore, the direct exposure to sun light post application of protein hair conditioners can be as harmful as exposure to gamma rays. The published work by Lee et.al.,[14] concluded that using a hair dryer at a distance of $15 \mathrm{~cm}$ with continuous motion causes less damage than drying hair naturally. Therefore, the authors affirmed that, even the exposure to normal environmental conditions especially in tropical areas, post conditioners applications can be a source of serious skin hygienic problems and may be induce cancer skin.

Table (3): The Severity of Histopathological Alterations in Skin of different Experimental Male and Female Rats

\begin{tabular}{|c|c|c|c|c|c|c|c|c|c|c|c|c|c|c|c|c|}
\hline \multirow[b]{2}{*}{ Alterations } & \multicolumn{8}{|c|}{ Male } & \multicolumn{8}{|c|}{ Female } \\
\hline & 1 & 2 & 3 & 4 & 5 & 6 & 7 & 8 & 1 & 2 & 3 & 4 & 5 & 6 & 7 & 8 \\
\hline Acanthosis of prickle cell layer of Epidermis & - & ++ & ++ & ++ & + & - & - & + & - & - & - & ++ & + & ++ & - & + \\
\hline Wrinkling in Epidermis & - & - & - & - & - & - & - & - & - & - & - & + & - & - & ++ & + \\
\hline Atrophy of Epidermis & - & - & - & - & - & - & - & - & - & - & - & - & - & - & ++ & ++ \\
\hline $\begin{array}{l}\text { Focal ulceration and necrosis in Epidermis\& } \\
\text { dermis }\end{array}$ & - & - & - & - & - & ++ & +++ & - & - & - & - & - & - & - & - & - \\
\hline Inflammatory reaction in subcutaneous tissue & - & - & +++ & ++ & - & ++ & ++ & - & - & - & - & - & - & - & - & - \\
\hline Migration of hair follicles & - & + & - & + & - & - & - & - & - & - & - & - & - & - & - & - \\
\hline $\begin{array}{l}\text { Inflammatory reaction and degeneration of skeleta } \\
\text { muscles }\end{array}$ & - & - & +++ & - & - & ++ & ++ & - & - & - & - & - & - & - & - & - \\
\hline
\end{tabular}

\section{$1:$ Group of control rats.}

2:Group of rats exposed to one time protein conditioner application followed by hot air.

3:Group of rats exposed to two times protein conditioner application followed by hot air.

4:Group of rats exposed to three times protein conditioner application followed by hot air.

5 :Group of rats exposed to one time protein conditioner application followed by hot air then single dose $\gamma$-rays.

6:Group of rats exposed to two times protein conditioner application followed by hot air then single dose $\gamma$-rays.

7:Group of rats exposed to three times protein conditioner application followed by hot air then single dose $\gamma$-rays.

8 :Group of rats exposed to one time protein conditioner application followed by single dose $\gamma$-rays. 


\section{CONCLUSION}

Based on the biochemical and histopathological data, it can concluded that repeated applications of a chosen first-grade protein hair conditioner followed by hot air and/or single dose 10 Gy gamma irradiation induced, in the best conditions, alopecia and mild eczema. While these treatments, in the worst case, lead to sever ulceration which can surpass to skin cancer.

Habitants in tropical hot area, like Egypt, are disclosing hot weather and very long period under ultraviolet rays. Whereas application of commercial protein hair conditioners and subdue this climate, certainly even by accumulation, will results in hair and skin hygienic disorders including cancers. Although the great progress in managing skin and hair diseases, yet the ethics of some cosmetic therapies, especially hair conditioners, still remain avoided. To meet this challenge, it is recommended to assert the hazard usage of these products even that stated they are "formaldehyde -free ".

\section{ACKNOWLEDGEMENTS}

The authors express their cordial thanks to the Egyptian Atomic Energy Authority for providing facilities to carry out this work.

\section{COMPETING INTERESTS}

The authors declare that there is no conflict of interests regarding the publication of this paper.

\section{REFERENCES}

[1] F.Ë. Bernerd, S. Del Bino, D. Asselineau. J. Invest Dermatol; 117:1421-9(2001).

[2] J.A. McGrath, R.A. Eady, FM. Pope. Rook's Textbook of Dermatology, $7^{\text {th }}$ ed. Blackwell Publishing; p. 3.1-3.6(2004).

[3] D. Breitkreutz, N. Mirancea, R. Nischt. Histochemistry and cell biology; $132(1)$ : 110(2009).

[4] J. Park, J.W. Lee, Y.C. Kim, M.R. Prausnitz. Int J Pharm; 359(1-2): 94-103(2008).

[5] A. McMichael, Keratin Hair Treatments Still Are Not Safe. Daily Health News; June 10 (2013).

[6] M.H. Maneli, P. Smith, N.P. Khumalo, J. Am. Acad Dermatol. ;70:276-80 (2014).
[7] J.D. Banchroft, A. Stevens, D.R. Tutner. Theory and practice of Histopathological technique. 4 th ed. Churchill Livingstone, New York, London, San Francisco, Tokyo. (1996).

[8] T. Fujii, J. Biol. Macromol.; 12(1): 3-15(2012).

[9] J.L. Mazzei, E.V. Figueiredo, L.J. da Veiga, C.A. Aiub, P.I. Guimarães, I. Felzenszwalb, J. Appl. Toxicol; 30:8-14(2010).

[10] J.S. Pierce, A. Abelmann, L.J. Spicer, R.E. Adams, M.E. Glynn, K. Neier, , et al. , J. Occu. Environ. Hyg. ;8(11):686-99 (2011).

[11] W.S. Simpson, G. Crawshaw, Wool: Science and Technology. Cambridge: Wood -head Publishing (2002).

[12] A.C.S. Nogueira, L.E. Dicelio, I. Joekes, Photochemical \&Photobiological Sciences; 5:165-9 (2006).

[13] E. Palma, D. Gomez, E. Galicia, V. Stolc, Y. Griko, Advances in Bioscience and Biotechnology ;7:1927(2016).

[14] Y. Lee, Y.D. Kim, H.J. Hyun, L.Q. Pi, X. Jin, W.S. Lee. Ann. Dermatol.; 23:455-62(2011).

[15] C.R. Robbins, Chemical and Physical Behavior of Human Hair. 5th ed., Berlin, Springer; p. 74. (2012).

[16] H. Zuo, P.M . Ueland, A. Ulvik, S.J.P.M. Eussen, S.E.Vollset, O. Nygård, et.al., Am. J . Epidemiol. ;183(4): 249-258(2016).

[17] S.Cho, M.H. Shin, Y.K. Kim, J.E. Seo1, Y.M. Lee, C.H. Park, et.al. Journal of Investigative Dermatology, Symposium Proceedings; 14:15-19 (2009).

[18] E.Y. Bryleva, L. Brundin, Neuropharmacology ;112: 324-30(2017).

[19] H.J. Zhang , L. Xu, V.J. Drake , L . Xie , L.W. Oberley , K.C. Kregel , FASEB J;17:2293-5 (2003).

[20] M.H. Shin , Y.J. Moon, J.E. Seo , Y. Lee , K.H. Kim , J.H. Chung, Free Radic. Biol. Med; 44:63545(2008).

[21] N. Begum, , N.R. Prasad, K. Thayalan, Int. J. Nutr.. Pharmacol Neurol. Dis. ;2 (1): 45-52 (2012).

[22] L. Van Lerberghe, M.A. Baeck, Contact Dermatitis; 70:384-6(2014) . 
[23] E.A. Craig, J.S. Weissman, A.L. Horwich, Cell; 78:365-72 (1994).

[24] E.N. Guerreiro, P. F. Giachetto, P.E.N. Givisiez, , J.A. Ferro, M.I.T. Ferro, J.E. Gabriel, et.al.,Brazilian Journal of Poultry Science ;6 (4): 201 - 206 (2004).

[25] B.H. Roh , D.H. Kim, M.K. Cho, M.D. Young , L. Park, K. Whang, Annals of Dermatology; 20 (4), (2008).

[26] P. Schildkopf , B. Frey, O.J. Ott, Y. Ruvner, G. Multhoff, R. Sauer , et.al., Oncothermia Journal;10:147-54 (2014).

[27] N. Yusuf , T.H. Nasti ， C.M. Huang , B.S. Huber , T. Jaleel , H.Y. Lin , et.al, J. Immunol;182(1): 675-83(2009).

[28] O.A. Ozen, N. Akpolat, A. Songur , I. Kuş , I. Zararsiz , V.H. Ozaçmak, Frontiers in Physiology,( 2017).

[29] N. Shiota, Y. Nishikori, E. Kakizoe, K. Shimoura, T. Niibayashi, C. Shimbori, et. al. , Int. Arch Allergy Immunol; 151: 80-8 (2002).

[30] P.J. Keck, S.D. Hauser, G. Krivi, K. Sanzo, T. Warren, J. Feder, et. al., Science; 246: 1309-12 (1989).
[31] M. Karimipour , V. Amanzade , N. Jabbari ， G.H. Farjah, Phys. Med.; 40: 104 -09(2017).

[32] F. Zhang, K. Fischer, E. Komorowska-Timek, M. Guo, D. Cui, W. Dorsett-Martin et. al. , Ann Plast Surg; 46: 314-19 (2001).

[33] M.S. Kim, Y.K. Kim, K.H. Cho, J.H. Chung, Br J Dermatol.;155,1131-8(2006).

[34] J.H. Chung, H.C. Eu, J. Dermatol.; 34:593600(2007).

[35] F. Lu, H. Mizuno, C.A. Uysal, X. Cai, Ogawa, H., Plast. Reconstr Surg; 121: 50-58(2008).

[36] C. Guruvayoorappan, G. Kuttan, J. Biological Science, 7(8):1511-1519 (2007).

[37] T. Kim, H.J. Na , W.R. Lee, S. Lee, Frontiers in Physiology; 11,125 (2015).

[38] A. Agarwal, A. Aponte-Mellado, B.J. Premkumar, A. Shaman, S. Gupta, Reprod Biol Endocrinol;10: 49 (2012).

[39] D.H. Deacon , K.T. Hogan , E.M. Swanson , K.A. Chianese-Bullock, C.E. Denlinge, A.R. Czarkowski, et.al., BMC Cancer, 8 :360(2008). 